\title{
Clinicomycological Profile and Antifungal Sensitivity Pattern of Commonly Used Azoles in Dermatophytosis
}

\author{
Mahesh Mathur, 'Shrujana Shrestha' \\ 'Department of Dermatology, College of Medical Sciences- Teaching Hospital, Bharatpur, Nepal.
}

\begin{abstract}
Introduction: Dermatophytosis is a common superficial fungal infection of the skin, hair and nails caused by Trichophyton, Microsporum and Epidermophyton dermatophytic species. Identification of causative dermatophytic species tend to vary with time and place and antifungal sensitivity is of epidemiological concern as well as significant for the treatment with precision at the current scenario of increasing antifungal resistance. To study clinicomycological profile and antifungal sensitivity pattern of commonly used azoles in dermatophytosis.
\end{abstract}

Methods: The prospective analysis of 145 clinically suspected cases of dermatophytosis was conducted from January 2014 to January 2015 at Department of Dermatology of COMS, Bharatpur, Chitwan, Nepal. Cases were evaluated and data recorded as per proforma. Samples were collected for microscopy and culture from skin, hair and nail. Antifungal sensitivity pattern was evaluated by standard disk diffusion technique.

Results: Maximum numbers of cases with dermatophytosis were observed between June to September with male to female ratio of 1.4:1. The youngest patient was 3 years and the oldest was 76 years. Tinea corporis $(25.5 \%)$ was the dominant clnical type observed. Overall direct microscopy $(\mathrm{KOH})$ positivity and culture positivity was $64.8 \%$ and $57.2 \%$ respectively. Predominant species of dermatophyte isolated was T. mentagrophyte (23.4\%). Out of five antifungals used in our study, fluconazole and ketoconazole were found $100 \%$ resistant.

Conclusions: This study highlighted the increasing resistance of the antifungals, which is responsible for the treatment failure in dermatophye infections.

Keywords: antifungal resistance; dermatophyte; epidemiology.

\section{INTRODUCTION}

The dermatophytes are a group of closely related fungi that have the capacity to invade keratinized tissue (skin, hair, and nails).

The prevalence of dermatophytosis varies throughout the globe and reported to be variable in different parts of the same continent. ${ }^{2}$ Chitwan bears subtropical climatic condition conducive for tinea infections. Sweating, maceration of the skin, occlusive footwear and comorbid conditions further add to the problem.

Currently, several antifungal drugs are available for the treatment but imidazoles and triazoles all of which target ergosterol biosynthesis of fungal membranes are the mainstay of treatment. ${ }^{3}$ Although, role of drug resistance in treatment failure is not clearly known but increasing resistance to these antifungal drugs has been observed in routine clinical practice and reported in literature. In-vitro susceptibility testing could help clinicians to select the proper antifungal agent. ${ }^{4}$

Prospective hospital based study was conducted to evaluate antifungal sensitivity pattern of dermatophyte isolates.

Correspondence: Dr. Shrujana Shrestha, Department of Dermatology, College of Medical Sciences- Teaching Hospital, Bharatpur, Nepal. Email: shrujana@gmail.com 


\section{METHODS}

A prospective hospital based study was conducted at the dermatology unit of College of Medical Sciences Teaching Hospital, Bharatpur, Chitwan from January 2014 to January 2015. One hundred and forty five patients of all age groups diagnosed clinically as dermatophyte infections not taking any form of treatments were included in the study with informed consent.

Skin scrapings were taken from active margin of suspected lesions after cleaning with $70 \%$ alcohol. Samples for culture was collected in sterile paper and was inoculated on Dermatophyte Test Agar Base (HIMEDIA- M188-500G, laboratories Pvt, Itd, India) with Dermato Supplement (HIMEDIA- FD015, laboratories Pvt, Itd, India) in test tubes and incubated at $30^{\circ} \mathrm{C}$ and checked daily on a routine basis for three weeks. If no growth observed at the end of three weeks, culture was labeled negative.

The identified dermatophyte colony was then grown in separate test tubes containing Rosewill Park Memorial Institute broth (Sigma- Aldrich Co. LLC, USA- R0883) for six hours. The harvested dermatophytes from each test tubes were then transfered to separate petridishes containing Sabouraud Dextrose Agar (HIMEDIA M063500G, laboratories Pvt, Itd, India).
Standard protocol for the Disk-Diffusion Method ${ }^{5}$ was used to determine the sensitivity for the commonly used antifungal drugs (HiMedia, laboratories Pvt, Itd, India) with respective potencies: ketoconazole $(10 \mathrm{mcg} /$ disc), itraconazole (30 mcg/ disc), clotrimazole (10 $\mathrm{mcg} / \mathrm{disc}$ ), miconazole (30 $\mathrm{mcg} / \mathrm{disc}$ ) and fluconazole (10 mcg/disc).

Then the antifungal discs were applied to the plates and were incubated at $25^{\circ} \mathrm{C}$ for 5- 10 days. Inhibition Zone Diameters (IZD) around the discs were measured and recorded. Criteria of susceptibility and resistance of antifungal discs were measured according to the standard protocol. ${ }^{5}$ In case of Clotrimazole, Miconazole and Itraconazole, they were considered sensitive if $I Z D \geq 12 \mathrm{~mm}$. Similarly IZD $\geq 15 \mathrm{~mm}$ and $I Z D \geq 23 \mathrm{~mm}$ were considered sensitive in case of Fluconazole and Ketoconazole respectively. ${ }^{5}$ Clinical photographs of patient along with culture characteristics and zone of inhibition were taken.

\section{RESULTS}

Total of 145 cases were included in the study, where age of the youngest patient was three years whereas age of the oldest male patient was 76 years. Cases between the age group 20-29 years were observed to be predominant. In our study, overall male $(58.6 \%)$ preponderance was observed with male to female ratio of $1.4: 1$.

\begin{tabular}{|c|c|c|c|c|c|c|c|c|c|c|}
\hline Diagnosis & $\begin{array}{l}\text { Total } \\
\text { Growth }\end{array}$ & $\begin{array}{l}E . \\
\text { floccosum } \\
(\%)\end{array}$ & $\begin{array}{l}M . \\
\text { canis } \\
(\%)\end{array}$ & $\begin{array}{l}\text { M. } \\
\text { gypseum } \\
(\%)\end{array}$ & $\begin{array}{l}T . \\
\text { mentagrophytes } \\
(\%)\end{array}$ & $\begin{array}{l}T . \\
\text { rubrum } \\
\text { (\%) }\end{array}$ & $\begin{array}{l}T . \\
\text { schoenleinii } \\
(\%)\end{array}$ & $\begin{array}{l}\text { T. tonsurans } \\
\text { (\%) }\end{array}$ & $\begin{array}{l}T . \\
\text { verrucosum } \\
(\%)\end{array}$ & $\begin{array}{l}\text { T. violaceum } \\
\text { (\%) }\end{array}$ \\
\hline $\begin{array}{l}\text { Tinea } \\
\text { barbae }\end{array}$ & 4 & $\begin{array}{l}1 \\
(25)\end{array}$ & 0 & 0 & $\begin{array}{l}3 \\
(75)\end{array}$ & 0 & 0 & 0 & 0 & 0 \\
\hline $\begin{array}{l}\text { Tinea } \\
\text { capitis }\end{array}$ & 10 & 0 & 0 & 0 & $\begin{array}{l}2 \\
(20)\end{array}$ & 0 & 0 & 0 & 0 & $\begin{array}{l}8 \\
(80)\end{array}$ \\
\hline $\begin{array}{l}\text { Tinea } \\
\text { corporis }\end{array}$ & 23 & $\begin{array}{l}8 \\
(34.8)\end{array}$ & 0 & $\begin{array}{l}3 \\
(13,0)\end{array}$ & $\begin{array}{l}9 \\
(39.1)\end{array}$ & 0 & 0 & $\begin{array}{l}1 \\
(4.3)\end{array}$ & $\begin{array}{l}2 \\
(8.7)\end{array}$ & 0 \\
\hline $\begin{array}{l}\text { Tinea } \\
\text { cruris }\end{array}$ & 17 & $\begin{array}{l}2 \\
(11.8)\end{array}$ & 0 & 0 & $\begin{array}{l}10 \\
(58.9)\end{array}$ & 0 & 0 & $\begin{array}{l}3 \\
(17.6)\end{array}$ & $\begin{array}{l}2 \\
(11.8)\end{array}$ & 0 \\
\hline $\begin{array}{l}\text { Tinea } \\
\text { facei }\end{array}$ & 6 & 0 & $\begin{array}{l}2 \\
(33.3)\end{array}$ & 0 & $\begin{array}{l}4 \\
(66.7)\end{array}$ & 0 & 0 & 0 & 0 & 0 \\
\hline $\begin{array}{l}\text { Tinea } \\
\text { manuum }\end{array}$ & 9 & $\begin{array}{l}1 \\
(11.1)\end{array}$ & 0 & 0 & $\begin{array}{l}3 \\
(33.3)\end{array}$ & $\begin{array}{l}4 \\
(44.4)\end{array}$ & $\begin{array}{l}1 \\
(11.1)\end{array}$ & 0 & 0 & 0 \\
\hline $\begin{array}{l}\text { Tinea } \\
\text { pedis }\end{array}$ & 7 & $\begin{array}{l}4 \\
(57.1)\end{array}$ & 0 & 0 & $\begin{array}{l}3 \\
(42.9)\end{array}$ & 0 & 0 & 0 & 0 & 0 \\
\hline $\begin{array}{l}\text { Tinea } \\
\text { unguium }\end{array}$ & 6 & $\begin{array}{l}3 \\
(50)\end{array}$ & 0 & 0 & $\begin{array}{l}1 \\
(16.7)\end{array}$ & $\begin{array}{l}2 \\
(33.3)\end{array}$ & 0 & 0 & 0 & 0 \\
\hline Total & 83 & $\begin{array}{l}19 \\
(22.9)\end{array}$ & $\begin{array}{l}2 \\
(2.4)\end{array}$ & $\begin{array}{l}3 \\
(3.6)\end{array}$ & $\begin{array}{l}34 \\
(41)\end{array}$ & $\begin{array}{l}6 \\
(7.2)\end{array}$ & $\begin{array}{l}3 \\
(3.6)\end{array}$ & $\begin{array}{l}4 \\
(4.8)\end{array}$ & $\begin{array}{l}4 \\
(4.8)\end{array}$ & $\begin{array}{l}8 \\
(9.6)\end{array}$ \\
\hline
\end{tabular}




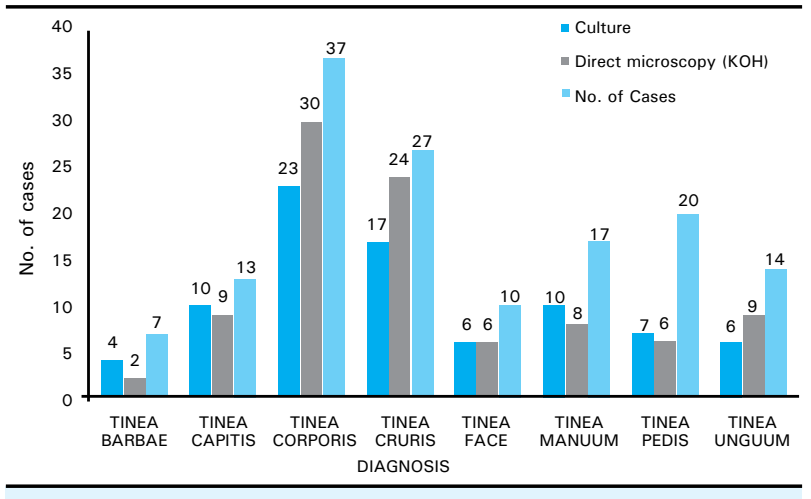

Figure 1. Bar diagram showing distribution of cases according to direct microscopy $(\mathrm{KOH})$ and culture positivity.

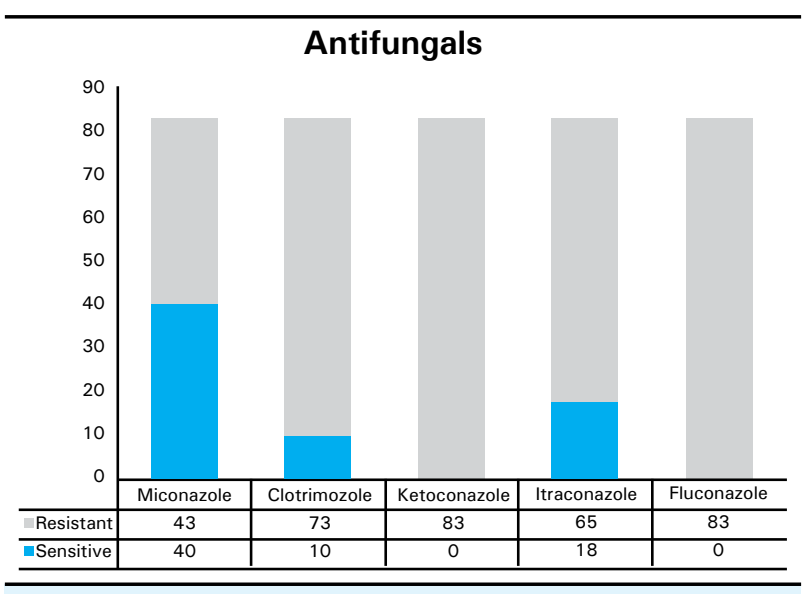

Figure 2. Bar diagram showing antifungal sensitivity pattern.

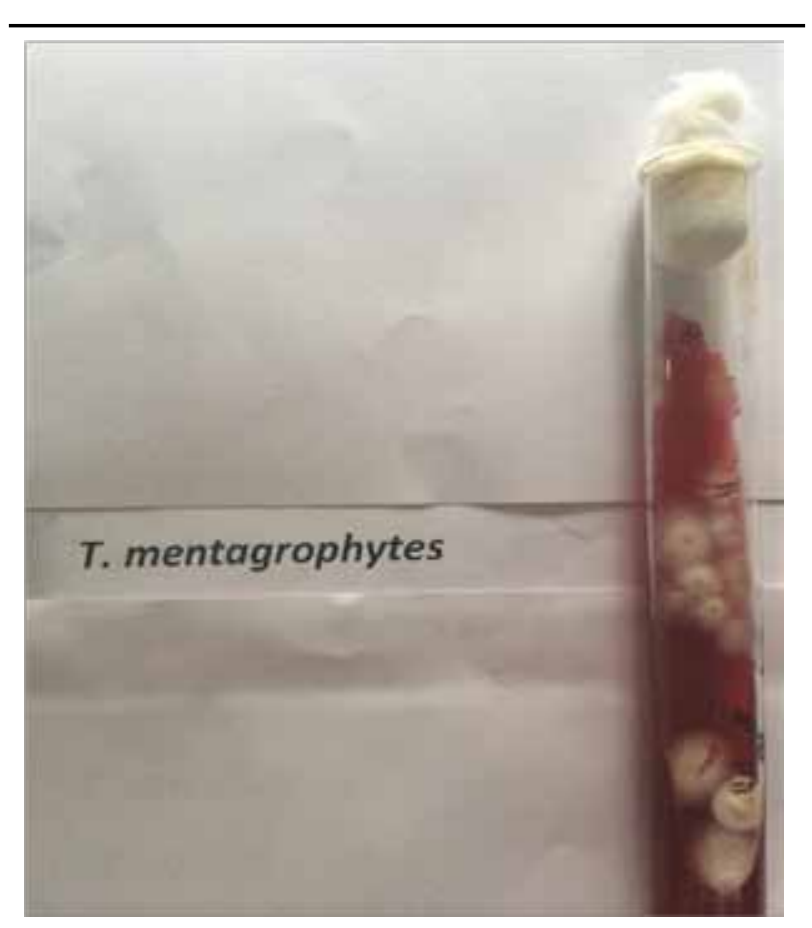

Figure 3. Trichophyton mentagrophytes- white powdery colony with creamy center.
In our study, maximum cases, $40(27.6 \%)$ were seen in the month of September. Majority of the cases, $86(59.3 \%)$ presented within five weeks of onset of disease. Most common clinical pattern in our study was tinea corporis $(25.5 \%)$.In the study, overall positivity of direct microscopy was $94(64.8 \%)$ out of 145 and culture positivity was $83(57.2 \%)$ out of 145 cases. (figure 1)

In this study, Trichophyton mentagrophyte (41\%) was predominantly isolated followed by Epidermophyte floccosum $(22.9 \%)$. (Table 1)

In our study resistance to antifungals were: fluconazole $(100 \%)$, Itraconazole (78.3\%), Ketoconazole (100\%), Clotrimazole (88\%) and Miconazole (52.8\%). (Figure 2)

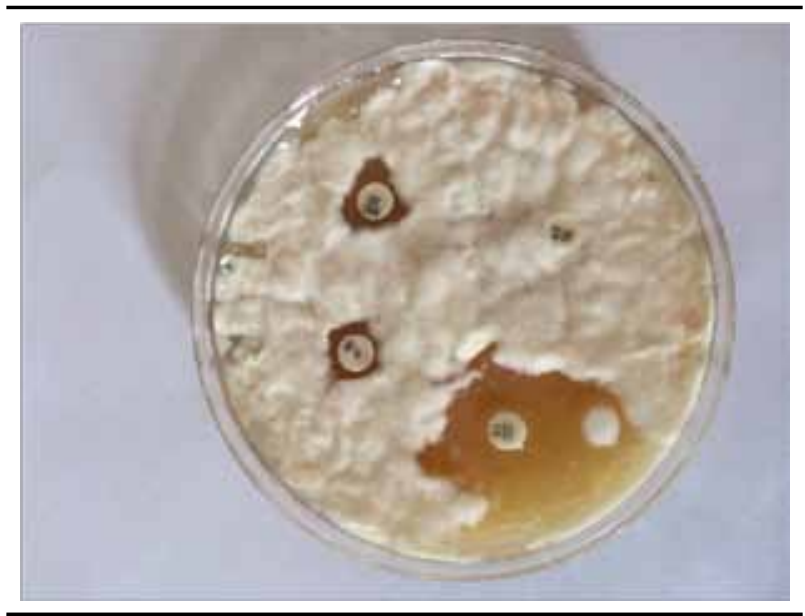

Figure 4. Antifungal sensitivity pattern (Trichophyton mentagrophytes).

\section{DISCUSSION}

Dermatophytic infection is ecumenical in distribution with increased frequencies in tropical and subtropical countries. In this prospective hospital based study, 145 cases of dermatophytosis were analysed. Maximum numbers of cases were observed between June to September when atmospheric temperature and humidity is conducive for tinea infections.

Male preponderance (58.6\%) was observed with male to female ratio of 1.4: 1 in our study, which is consistent to previous studies ${ }^{6,7}$ Such higher prevalence of dermatophytosis in males may be due to the differences in occupational exposure as males are more involved in exhaustive physical work and prolonged exposure to sun leading to excessive sweating which predispose for the tinea infection.

Tinea corporis $(25.5 \%)$ was the dominant clinical type of dermatophytosis observed in our study followed by tinea cruris $(18.6 \%)$ as reported in literature. ${ }^{8,9}$ 
In present study, overall direct microscopic examination $(\mathrm{KOH})$ positivity was $64.8 \%$ (figure 1 ), which is similar to our previous study. ${ }^{10}$

In this study, overall culture positivity was observed in $57.2 \%$ of cases. (figure. 1 ), while it was reported rather low in prior studies. High positivity in our study is because of the use of selective media (Dermatophyte Test Medium), which does not allow contaminants to grow.

T. rubrum is the dominant species reported worldwide $6,11,12$ but Epidermophyton as a dominant species followed by $\mathrm{T}$. rubrum and $\mathrm{T}$. mentagrophytes as predominant species followed by $T$. rubrum has also been reported. ${ }^{13,7}$ In contrast, our study revealed Trichophyton mentagrophytes $(23.4 \%)$ as a predominant species identified followed by Epidermophyton floccosum (13.0\%), T. violaceum (5.5\%), and T. rubrum $(4.1 \%)$. (table. 1$)$. The plausible explanation for this may be that $T$. rubrum is generally linked to chronic dermatophytosis. Further, this organism is a slow growing organism, there is a possibility that other dermatophyte species might overgrow or mask the growth of $\mathrm{T}$. rubrum while attempting isolation. 7 However, species of fungus causing different types of clinical disease may vary from time to time.

In our study, sensitivity to antifungal drugs were: Miconazole (48.2\%), Clotrimazole (12\%), Ketoconazole (0), Itraconazole (27.7\%), Fluconazole (0) (figure 2) which is in accordance to study conducted by Pakshir et al. (2009). ${ }^{5}$ Fernandez-Torres $(2001)^{14}$ and Sarifakioglu $(2007)^{15}$ reported fluconazole as the least active antifungal agent, with great variation in MIC values. Our study is a single center study and is performed first time in Nepal but nationwide multi- center trial should be carried out to address the severity of antifungal drug resistance in Nepal.
Finally, in view of high level of resistance of commonly used antifungal drugs, treatment plans should be revised. Recent studies reported that antimicrobial of plants have limitless ability to synthesize secondary metabolites to treat various bacterial and fungal infections. The use of medicinal plants in the treatment of dermatophytosis will help to reduce the dependence on the use of microbial or chemically synthesized antimicrobials and thus overcome the problem of the emergence of fungi being resistant to antifungal.

\section{CONCLUSIONS}

Fungal species identification is mandatory when prolonged course of antifungal treatment is required and treatment may be prescribed with precision rather than empirically. Furthermore culture of specimen should be performed especially in cases of tinea pedis and tinea unguium to improve diagnosis when prolong antifungal treatment is required.

Out of the five antifungals included in the study, fluconazole and ketoconazole were found completely resistant to all the species isolated. However, Itraconazole, Miconazole and clotimazole showed relative sensitivity, which suggests the increasing resistance of the antifungals drugs, which may be responsible for the exceeding cause of treatment failure in dermatophyte infections. Such increasing fungal resistance is quite a challenge to the field of medicine, which demands the wise selection of antifungals by the physicians.

\section{ACKNOWLEDGEMENTS}

Dr. B.K. Jha, Department of Microbiology and colleagues of Department of Dermatology for technical supports.

\section{REFERENCES}

1. Weitzman I, Summerbell RC. The dermatophytes. Clin Microbiol Rev 1995; 8(2); 240-59

2. Ajello L. Present day concepts in the dermatophytes. Mycopathol Mycol Appl 1962; 17: 315-24.

3. Esteban A, Abarca ML, Cabanes FJ. Comparison of disk diffusion method and broth microdillution method for antifungal susceptibility testing of dermatophytes. Med Mycol 2005; 43: 61-6

4. Fernandez-Torres B, Carrillo AJ, Martín E, Palacio A, Moore MK, Valverde A, et al. In vitro activity of ten antifungal drugs against 508 dermatophyte strains.Antimicrob Agents Chemother 2001; 45(9): 2524-8.

5. Pakshir K, Bahaedinie L, Rezaei Z, Sodaifi M, Zomorodian K. In vitro activity of six antifungal drugs against clinically important dermatophytes. Jundishapur J Microbiol 2009; 2(4): 158-63
6. Bindu V. Clinico - Mycological study of dermatophytosis in Calicut. Indian J Dermatol venereol Leorol 2003; 69: 281-3.

7. Bhatia VK, Sharma PC. Epidemiological studies on Dermatophytosis in human patients in Himachal Pradesh, India. Springer Plus 2014; 3:134-40.

8. Agrawalla A, Jacob M, Sethi M, Parija SC, Singh NP. A Clinico- Mycological Study of Dermatophytoses in Nepal. J Dermatol 2001; 28(1): 16-21.

9. Singh S, Beena PM. Profile of dermatophyte infections in Baroda. Indian J Dermatol Venereol Leorol 2003; 69: 281-3.

10. Mathur M, Kedia SK, Ghimire RBK. Epizoonosis of Dermatophytosis: A clinico- mycological study of dermatophytic infections in Central Nepal. Kathmandu Univ Med J 2012; 37(1): 30-3. 
11. Omar AA. Importance of mycological confirmation of clinically suspected cases of tinea corporis, tinea pedis and tinea cruris. J Egypt Public Health Assoc 2004; 79(1-2): 43-58.

12. Maslen MM. Human cases of cattle ringworm due to Trichophyton verrcosum in Victoria, Australia. Australasian Journal of Dermatology 2001; 41(2): 90-4.

13. Bassiri-Jahromi S, Khaksari AA. Epidemiological survey of dermatophytosis in Tehran, Iran, from 2000 to 2005. Indian J Dermatol Venereol Leorol 2009; 75: 142-7.
14. Fernandez-Torres B, Carrillo AJ, Martín E, Palacio A, Moore MK, Valverde A, et al. In vitro activity of ten antifungal drugs against 508 dermatophyte strains.Antimicrob Agents Chemother 2001; 45(9): 2524-8.

15. Sarifakioglu E, Seckin M, Demirbilek, Can F. In vitro antifungal susceptibility patterns of dermatophyte strains causing tinea unguium. Clin Exp Dermatol 2007; 32(6): 675-9.

16. Balakumar S, Rajan S, Thirunalasundari $T$, Jeeva $S$. Epidemiology of dermatophytosis in and around tiruchirapalli. Asian Pacific Journal of Tropical Disease 2012; 2(4): 286-9. 